\title{
Planning a Sustainable New City
}

\author{
Spiro N. Pollalis ${ }^{*}$, Angela Kouveli ${ }^{2}$, Yannis Orfanos $^{1}$, Olga Tzioti ${ }^{3}$ \\ ${ }^{1}$ Harvard Design School, Cambridge, USA \\ ${ }^{2}$ Planning and Development Department, Hellinikon SA, Athens, Greece \\ ${ }^{3}$ Prof. Dr. S.N. Pollalis Inc., Belmont, USA \\ Email: ${ }^{*}$ pollalis@gsd.harvard.edu
}

Received 16 December 2013; revised 31 January 2014; accepted 11 February 2014

Copyright (C) 2014 by authors and Scientific Research Publishing Inc.

This work is licensed under the Creative Commons Attribution International License (CC BY). http://creativecommons.org/licenses/by/4.0/

(c) (i) Open Access

\section{Abstract}

Pakistan, the sixth most populous country with 185 million people, grows in the last years at approximately 3.2 million people per year, generating a strong demand for new urban areas [1]. The Defense Housing Authority (DHA), among Pakistan's most reputable land developers, has been instrumental in providing land for both residential and commercial use in several metropolitan areas. In Karachi, DHA has provided urban land in phases, with such land being most desirable to live and work, significantly improving the existing stock and allowing the growth of competitive economic activities. When DHA started Phase 10, at a distance of $55 \mathrm{~km}$ from the center of Karachi, the objective became to develop a self-sustained new city, although it should function as a satellite to the main metropolitan area. Pakistan has had a best experience from the planning of Islamabad by the legendary planner Constantinos Doxiadis, based on the Ekistics concept. So, the planners for the new city, called DHA City Karachi (DCK), also followed the Ekistics concept, enhanced to address the sustainability requirements of DHA. The resulting highly complex planning process, resulting from an uneven terrain and an irregular boundary, was possible to be carried out by employing advanced computer algorithms in the form of parametric design and GIS, tools that were unavailable to Doxiadis in the $60 \mathrm{~s}$ but fascinated him at the end of his professional life. This paper presents the sustainable planning approach for the new city of 600,000 people, handling physical constrains and site issues whilst ensuring adaptation to context. Then, the paper introduces how computing was employed towards applying Ekistics.

\section{Keywords}

Sustainable Planning; Mixed Use Development; Sustainable Infrastructure; Ekistics; Computational Design

\footnotetext{
"Corresponding author.
} 


\section{Introduction}

In 2010, DHA, following an international competition, contracted with the Osmani Group, Doxiadis Associates and RMJM, to plan the new DHA City Karachi (DCK). Prof. Spiro N. Pollalis, a Doxiadis scholar and practitioner, was appointed as the chief planner of the consultants for creating a model sustainable city of international appeal. When contracted, DHA had already sold almost 25,000 plots to individuals, ranging from 200 sqyrds to 2000 sqyrds with most plots at 500 sqyrds. Initially, the new city was conceived as a bedroom community to Karachi. However, its distance from the center of the city dictated a more integral approach towards a self-sufficient mixed-use city.

\section{Project Site and Requirements}

\subsection{City Location}

DCK is approximately 44 square $\mathrm{km}$, situated inland, to the east of Karachi. The distance to the city center of Karachi, the largest seaport and economic hub of Pakistan, is $56 \mathrm{~km}$ and it is $30 \mathrm{~km}$ away from the Jinnah International Airport of Karachi. DCK is near the cities of Hyderabad, Thatta and Jamshoro and the Karachi-Hyderabad Super Highway is its northern boundary.

\subsection{Scale in Relation to Other International Metropolitan Centers}

As a first step, a comparison with other metropolitan areas was carried out to understand the scale of the site. Islamabad, the capital of Pakistan designed by C. Doxiadis, New York, Zurich and Athens were laid over the site. The comparison showed that that DCK covers 14 sectors (each $1.5 \times 1.5 \mathrm{~km}$ ) of Islamabad, an area similar in size to Manhattan, all the metropolitan area of Zurich and the entire center of Athens. Within this framework, DCK was considered and designed as a self-sufficient urban entity, incorporating the attributes of a sustainable and livable metropolitan center.

\subsection{Physical Constraints and Site Issues}

Numerous hills and a dense network of streams (nullahs) originating from the Malir River at the southwest of DCK, shape the overall landscape of the site. A dramatic physical characteristic forming a unique topography is defined by a $70 \mathrm{~m}$ high ridge, which extends along the site's south boundary, dividing the area of the new city into two distinctive parts. Due to the low annual precipitation and the area's subtropical/dry climate, there is lack of water reservoirs in the area, but with sufficient quantities of water at the aquifer. The level of average annual precipitation is rather low and unusual for Pakistan and rainfalls peak during the monsoon period from July to August.

Air pollution from an adjacent cement factory at the northeast boundary of the site was a significant constraint. However, the prevailing southwest-northeast winds alleviate the problem of air quality.

\subsection{Program, Land Uses and Standardized Plots}

DCK has been envisioned as a model residential development with the aim to achieve a balance among environmental, social and economic sustainability. Incorporated supra-regional facilities within a proposed network of local activities form the connective tissue of the development. The creation of lively communities defined by both the new city's future residents and the visitors, residents of the adjacent urban centers including Karachi, will promote DCK to be a safe urban hub.

The initial estimate for required land uses is in accordance with the Karachi planning regulations (KBTPR). The breakdown of the planned land use is residential 55\%, green and open areas 13\%, retail 5\%, street network $22 \%$, and other uses $5 \%$.

The starting element for planning was the land division to provide the pre-sold residential and commercial plots. These plots should be orthogonal with standard dimensions, to fulfill the promise of DHA to the buyers.

\subsection{Social Cohesion}

With limited planning and a constant influx of migrants, Karachi, a 19-million-population urban center, ranks low among international city centers regarding the quality of its livable environment [2]. In contrast to the de- 
veloped western countries and cities with higher quality standards, Karachi lacks upgraded infrastructures and utilities, and it is in need for improved public health, water supply and energy.

\section{Main Design Principles}

\subsection{Social Parameters as Strategic Directions for Design}

The objective in planning DCK was firstly to provide quality infrastructure such as safe and abundant potable water, security, proximity to daily activities, non-polluted neighborhoods, social services as well as to ensure viability and sustainability. Planned under the umbrella of the Ekistics concept (Figure 1) and sustainability, DCK aims to become a prototype city of urban design and planning for Pakistan and the region.

\subsection{Masterplan and Urban Design in Relation to Context and the Ekistics Theory}

The irregular contour of DCK's boundary, in combination with its topographical relief, provided an excellent setting of expanding Ekistics from the traditional flat squares of Islamabad to the dynamic, organic shapes of DCK (Figure 2).

The preservation of the topography of the natural landscape, including the relief, the streams, the ridge, and the flood areas, and their incorporation in the urban fabric became a fundamental design strategy, possible only with advanced computing techniques.

At the same time, observing the concept Ideal Dynapolis of Doxiadis [3], we planned a linear city center crossing the site to form the backbone of a possible future expansion of the center and the city itself. The selected axis was organic and curved, connecting Karachi through the Super Highway to the north with the future Education City, which is under planning, to the west.

The land use distribution and road network were organized on an organic grid determined by the relief of the landscape and the boundaries of the site, forming 16 distinctive sections (sectors). The sectors have been planned to function as autonomous urban units, with multiple local centers, being self-sufficient in terms of everyday facilities and services.

The multi-center system of the Ekistics theory [3], already familiar to Pakistanis through Islamabad's design, is based on a fractal division of sectors into sub-sectors. Every sector is divided into four communities: class IV communities or subsectors. As shown in Figure 3, these in turn consist of smaller communities: class III communities or neighborhoods. Three types of centers (c5, c4, c3) emerge, each one with specific land uses. The latter serve the three scales of residential areas: sector, subsector and neighborhood respectively. The number of communities and the centers' size and land use depend on their estimated population, which depends on the area that is determined by the irregular boundaries, as well as the size of the plots, as different plot sizes produce a different population density.

\subsection{Self-Sufficiency and Resources}

The reduction of energy consumption and mitigating climate change were taken into consideration in planning.

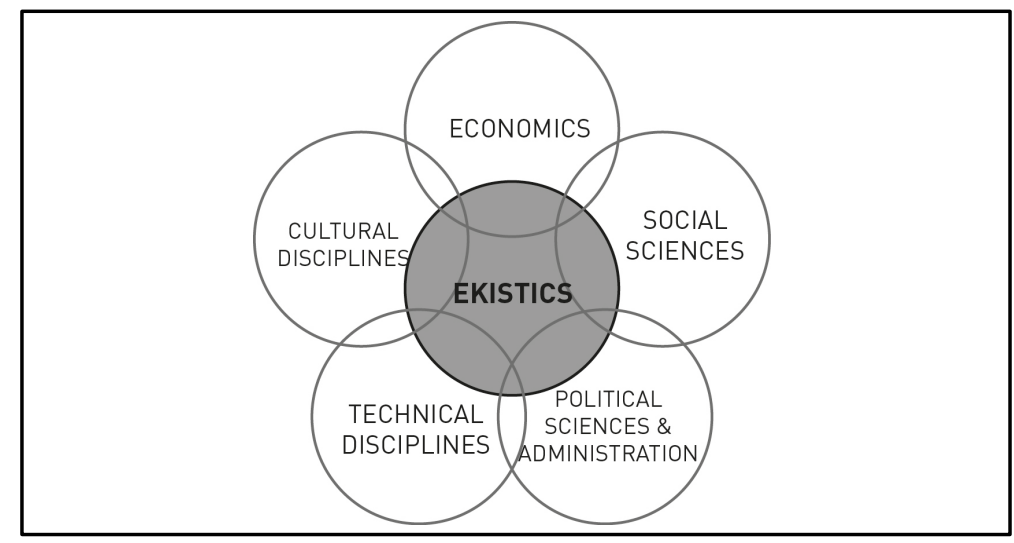

Figure 1. Diagram of Doxiadis’s concept of the Ekistics theory. 


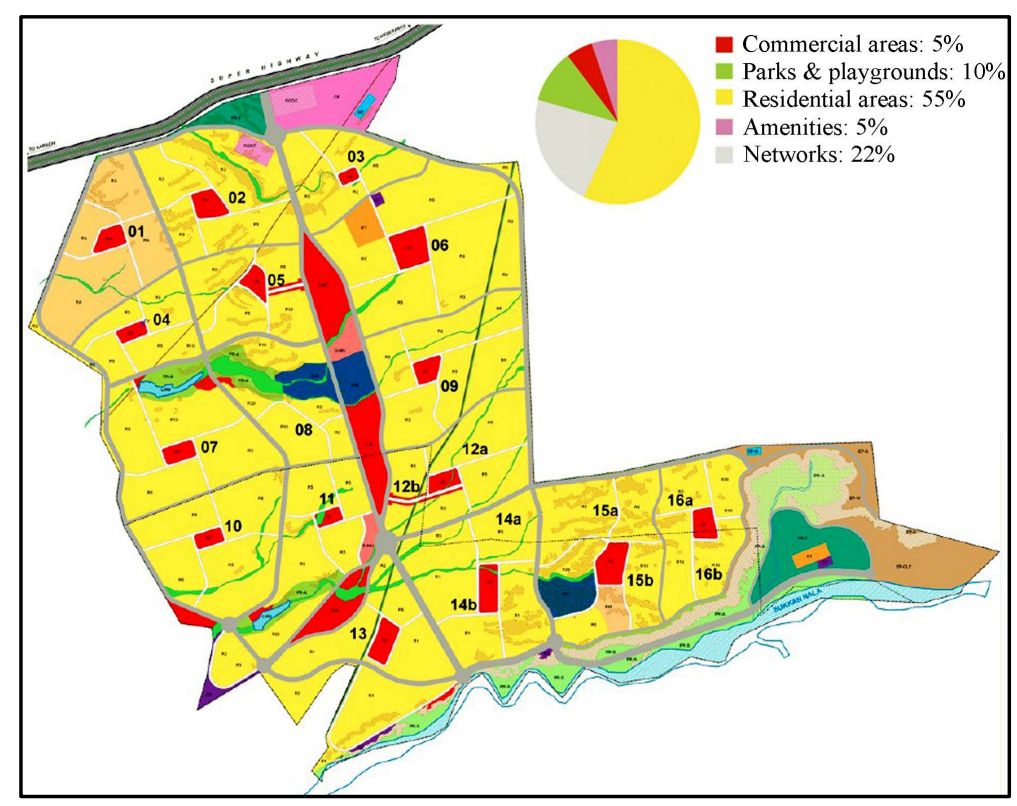

Figure 2. DCK land-use plan.

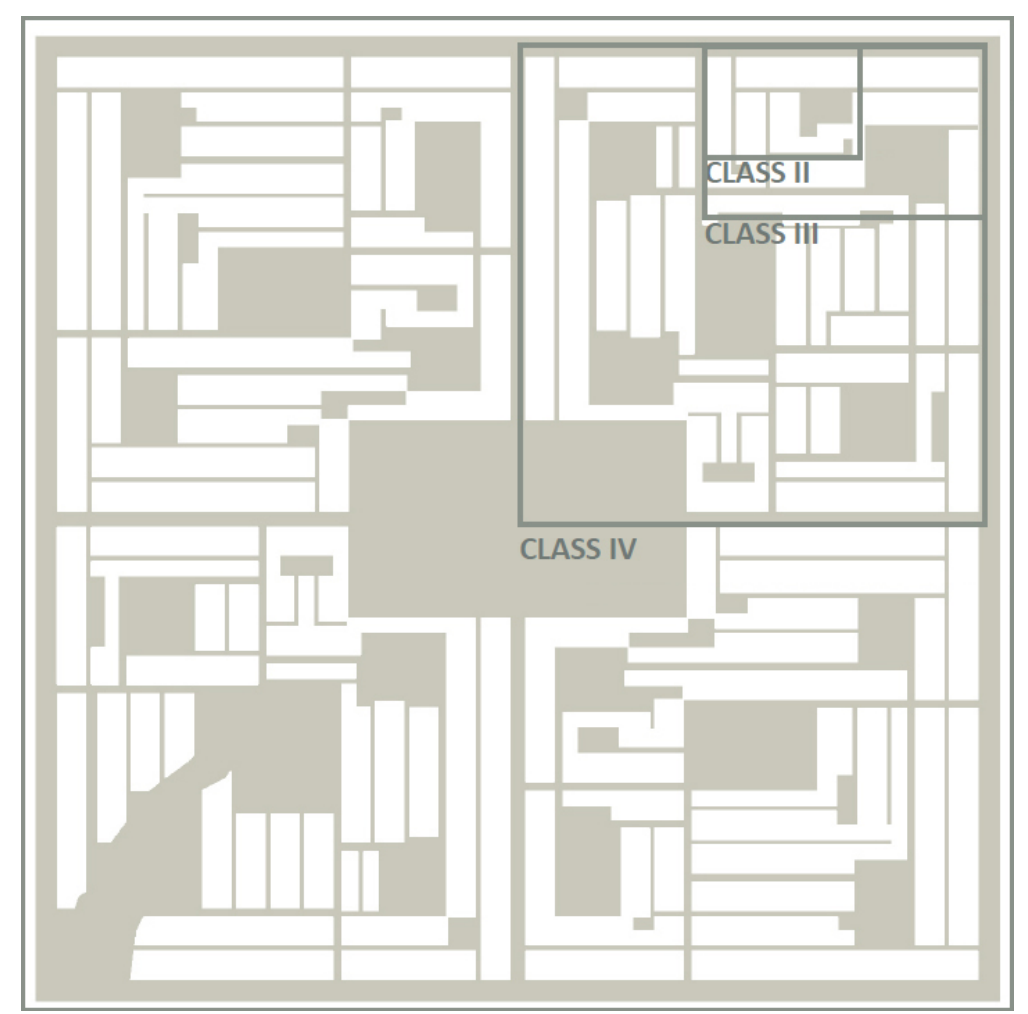

Figure 3. Multi-center system diagram mapped on the boundaries of each sector.

Therefore the strategic location and linear form of the Central Business District (CBD), contributed in the reduction of using private cars. It is estimated that the maximum time required to reach the city center by car is approximately 15 minutes. At the same time, the street network orientation is aligned with the direction of streams and green corridors, allowing for prevailing winds to cross the urban fabric, enhancing natural ventilation. In addition to the multifunctional land uses of the CBD, each sector's multiple mixed use community centers are 
strategically located in order to reduce average walking distances between the centers and residences to 2 - 10 minutes (Figure 4).

Based on the general energy strategy of Pakistan, DCK's energy strategy aims to achieve $30 \%$ of the total required energy from renewable energy sources, such as $10 \%$ from wind, $5 \%$ from solar, $10 \%$ from biomass and $5 \%$ from waste to energy.

At the same time, it is fundamental to have a minimum dependence on water outside the site. So, we framed the water management strategy by creating two small lakes with the construction of two small dams for rainwater management, the distribution of a distributed network of sewage treatment plans and the reuse of treated wastewater as gray water for domestic use and for irrigation.

\subsection{Ekistics and Sustainability}

The Ekistics concept and sustainability have a twofold association in the planning procedure of the new DHA City Karachi (DCK).

First, Ekistics is approached as a concept that introduces fundamental design principles, which promote the social, environmental and economic sustainability of a new city. Specifically, the Ekistics concept is articulated around the combination of the five elements: man, nature, society, shells and networks. The planning of DCK was based on addressing the economic aspect of plots, the physical constraints of the site, the quality and efficiency of the urban environment, the self-sufficiency of the community, and reliable infrastructure networks.

Second, the Ekistics concept provided a design framework through the Community Class system that proved critical for achieving integrated urban planning across different scales. The multi-scalar spatial organization dimension of Ekistics facilitated all design stakeholders to attach specific input on sustainability issues across different scientific fields and different scales. The Ekistics spatial framework played an important role on decoding problems and embedding sustainable solutions.

In planning DCK, the extensiveness of the usability and applicability of Ekistics was revealed. The Ekistics concept is a sophisticated system for thinkers and practitioners, which was developed further using contemporary technological means and therefore we engaged it in addressing the urban challenges of this project.

\section{Research Fields and Innovation}

\subsection{A New Approach on Ekistics}

\subsubsection{Digital Technologies and Ekistics}

The application of state-of-the-art computing technologies played an important role during the design process of DCK, so that the complex demands of the project were confronted holistically, accurately and fast. So, the response to the imminent planning needs of the project and research formed a parallel process, where one part was reinforcing the other, producing innovative methods and systemic tools. The central methodology focused on the modification of the hierarchical structure of Ekistics to a flexible hierarchical system (Figure 5). The qualitative and quantitative criteria of Ekistic units are translated to a system that incorporates information technology in combination with contemporary planning methods and techniques.

\subsubsection{Systemizing Ekistics}

A new approach on Ekistics has been developed to respond both to the need for informational feed to the design process and embodiment of the urban planning qualities of C. Doxiadis' Ekistics system. Fundamentally, Ekistics were approached simultaneously as a design and analysis tool, possible with the integration of computational techniques. Therefore, while as a design principle it was guiding the distribution of Communities Classes throughout various scales in the master plan, it was operating simultaneously as an evaluation medium that provided data on population, urban density, land use areas, energy \& water demand, length and surface of the road network. Since the original concept of Ekistics concerned the harmonious allocation of populations across neighborhoods in an inter-scalar interconnected system, the formation of residential sectors was directly affected by the computational output. Another basic upgrade on Ekistics was implemented through the integration of Ekistics' qualities, such as walking proximity, controlled-moderate population density, and equitable distribution of public spaces. Thus, the master plan approach went beyond the orthogonal forms and was adjusted to free-form geometries imposed by the terrain and formulated through computational design. 


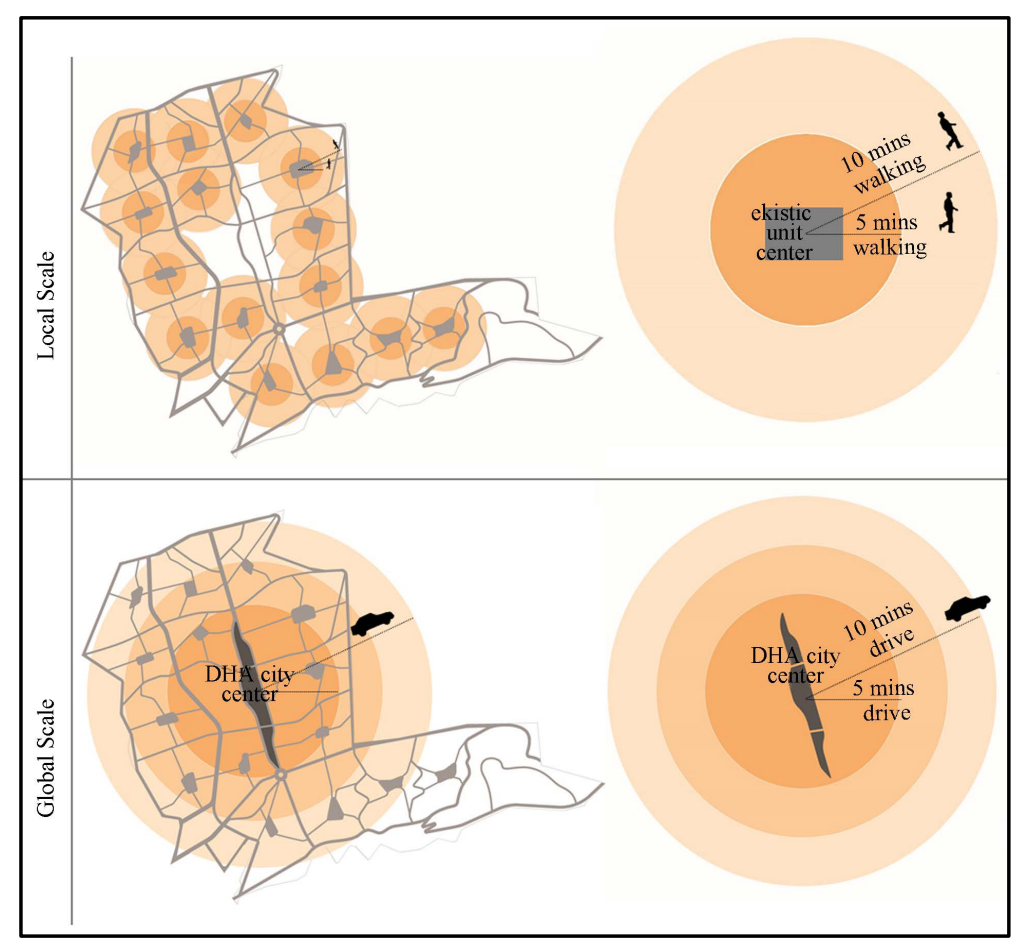

Figure 4. Proximities to mixed-used centers-sector and city scale.

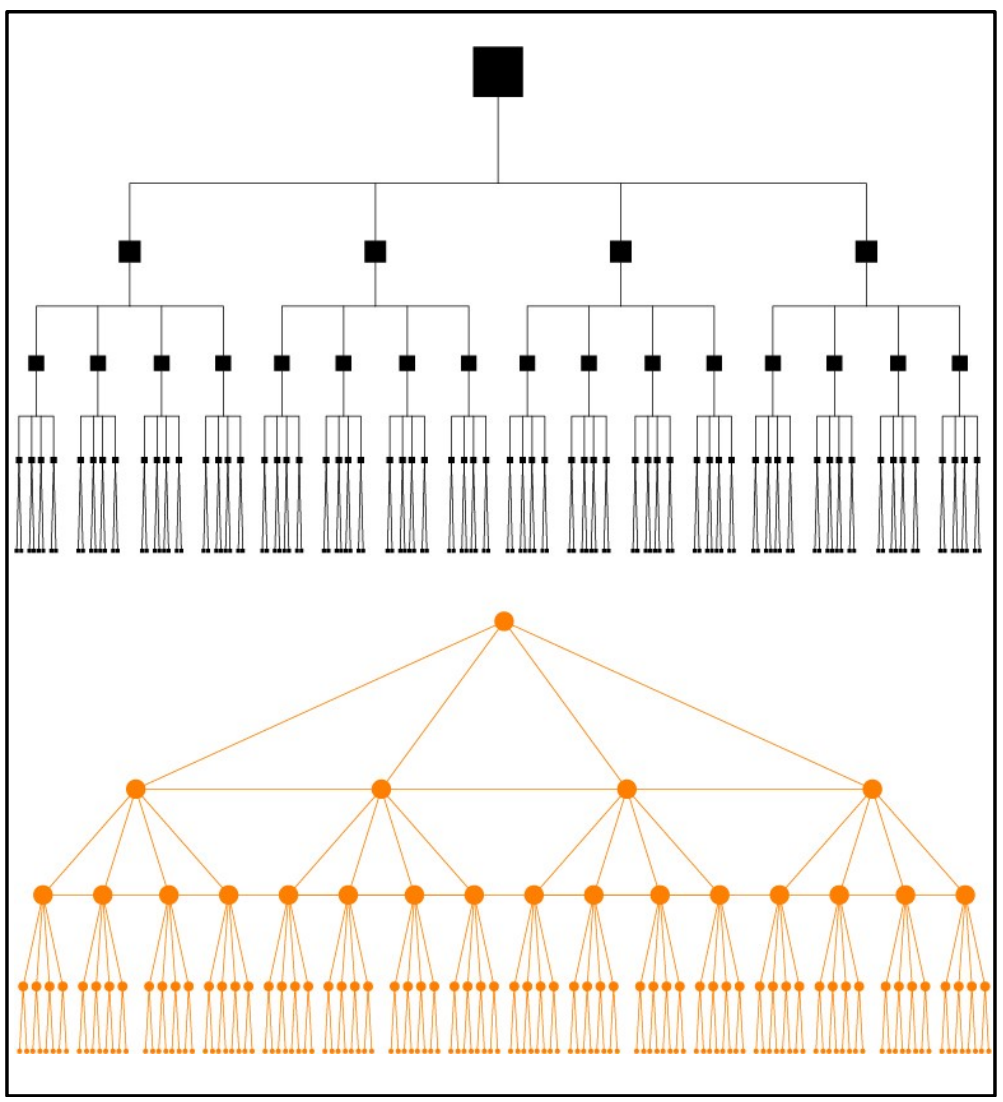

Figure 5. Modifying the hierarchical structure of Ekistics to a flexible hierarchical system. 


\subsection{Parametrization of Urban Design}

The implementation of the aforementioned elements has been realized in multiple levels and phases of the project: from the main project management strategies to the simulation techniques of 3D volumes. One of the central challenges of the project was the configuration of areas through the allocation of plots of predefined sizes (200 to 2000 square yards). This decision was critical, since it would define the development character of each area of DCK, configure the population distribution implicating intensity of activities and transportation loads, and respond to the overall economic and technical development brief. Therefore, the residential sectors are bound through parameters, such as the categorization of the plot sizes, the respective population, equivalence to the total percentage of pre-sold plots, and the development phases of the city. Thereupon, the study and management of different scenaria of development was feasible and could produce results quickly.

A similar logic of a holistic design management at the master plan scale was used for locating the centers in the residential sectors. The parametrization of the rules of Ekistics on deploying centers in each community category facilitated the feasibility studies of different scenaria in the sectors, mainly for Community Class V, by adjusting the spatial territory, population, building density, building regulations and the physical constraints such as ridges and streams on the area.

\subsubsection{Adjustment to the Terrain}

DCK is located in an area of complex topography that implies high slopes in residential areas. Slope analysis was necessary in order to identify the appropriate areas with low slopes that permit construction. Slope analysis was implemented through various levels of criteria concluding to three basic scenaria of earthworks: 1) keep all ridges, 2) keep ridges more than $10 \mathrm{ft}$ high and with more than $15 \%$ slope and 3) flat the entire site. Due to the size of the site, the costs for options 1) and 2) were prohibitive and the cost of 3) was chosen the optimal. Furthermore, floods are common in the area, resulting from sudden rainfalls. Thus, the accumulation of water in the low areas of the site was analyzed and followed by the designation of the safe areas for urbanization. The low areas were designated for the creation of artificial lakes contributing to the water supply of the city.

\subsubsection{Parametrization of Urban Design}

The multitude of the experts and the complexity of the factors that influenced the design under highly tight schedules, were managed by the parametrization of some of the most critical elements in the planning process. The implementation concerned the designation of the smallest "ekistic" community (Community Class II) to be parametrized and then being optimized through the modification of variables. Different types of plots configure a genealogy of multiple variations that are generated by the codification of the dimensions of the plots, street width, plot orientation, drainage, and the geometry of the ekistics community outline.

This process was enriched during the execution of the project, since the need rose for a detailed analysis and evaluation of the respective road construction earthworks that are required in each sector and each partial Ekistics community. The variable of the slopes of roads was added, so that in each design-arrangement of neighborhood scale, a road categorization was generated in real time. Roads were categorized in segments that did not require earthworks, in segments that earthworks were necessary, and in segments that earthworks were possible but economically undesirable.

\subsubsection{Optimization of the Planning Process}

Each residential sector contains a different number of centers: C5, C4, and C3. Each center, according to its classification and the population distribution of the sector, has a different size (Figure 6). Furthermore, because of the irregular boundaries and the topographic relief, each center has a distinct shape. The resulting relations are connected parametrically with the main design directions of the centers, so that the spatial arrangement of the different land uses is assisted through parametric design. Particularly, due to the large number of case centers C3, with 12 centers per sector in average, automation provided a better control of data and changes.

\subsubsection{D Parametric Simulation}

Computational techniques were applied for the three-dimensional simulation of the buildings at the residential sector level. The design ranges from planning large scale areas to the designation of the shapes of the plots called for an efficient way to represent multi-scalar proposals. This was achieved through the parametric association 


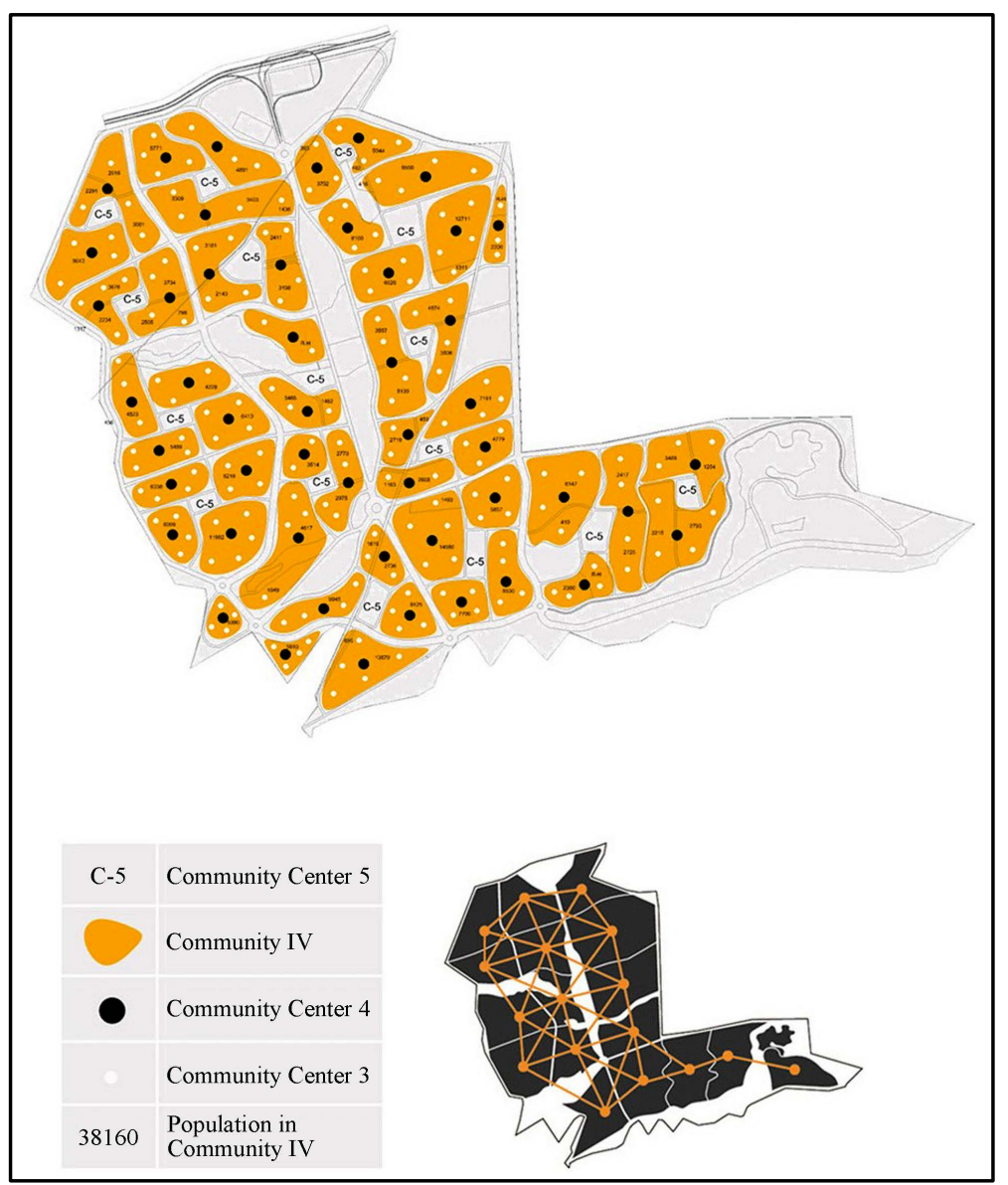

Figure 6. Distribution of community centers of variable number and size across the sectors.

of plots with the building regulations that give instructions on locating the buildings inside the plots. Based on the permitted building footprint and floor areas, a three-dimensional massing simulation was generated in multiple options achieving maximum coverage. Thereafter, the building volumes were adjusted parametrically in the three-dimensional terrain (e.g. 6500 buildings in sector 6), in order to provide both general and detailed views. Then, by using the 3D representation of building volumes in the centers C5 and C4, shading analyses were conducted to assess the impact on public spaces and commercial areas.

\subsection{Geographic Information Systems (GIS) as a Tool for Sustainable Planning}

Beyond a sustainable master plan, an important feature in planning a sustainable city is its infrastructure. It is the set of physical systems, services, and networks that support the society of a city for achieving economic prosperity while protecting the natural systems and providing high quality of life. Infrastructure entities, networks and systems are organized under seven main types of Infrastructure that support the whole function of the city: Energy, Water, Waste, Landscape, Transportation, Information and Food [4].

Infrastructure Planning in DCK was approached first by decoding and second by evaluating the infrastructure systems and the interconnections, conflicts and relationships of the entities. Their final design was based on sustainability objectives.

A platform collecting information on various scales was continuously developing in order to provide a database initially for parametric design, and later for the control and management of the project in the next phases of detailed planning, construction and operation. The database contains basic metrics on land uses, areas, zoning, population, FAR, regulations, phasing strategy etc. related to the master plan.

Geographic Information Systems were used to initially upgrade the collected data to data with identified geo- 
graphic location to facilitate the processes of automated mapping, visualizing and interpreting the data related to the infrastructure systems at any scale.

In combination with the master plan database, metrics on noise pollution, materiality, shading, $\mathrm{CO}_{2}$ emissions, proximities to city attractors, energy consumption, water demand, waste generation, and landscaping were carefully analyzed and mapped in order to create a tool that allows for a continuous evaluation of infrastructure planning alternatives, with regard to the sustainable objectives. Through this multiple-criteria-decision-making tool, we secured an overall surveillance of infrastructure interrelations, synergies and impacts, contributing to a holistic sustainable planning across all infrastructure systems and scales throughout the whole city.

\section{Conclusions}

Ekistics formed the basis of the planning of DCK. The theory of Ekistics was extended to include sustainability of both the master plan and the infrastructure as a key driver of the planning process, respecting the natural world and the relief of the landscape. In parallel to determining land uses, the planners considered the proper infrastructure: energy, water, solid waste, transportation and food, to address sustainability issues at the scale of both the city and its neighborhoods. Furthermore, socio-economic conditions were considered in relation to the environmental and climate characteristics to form a dynamic system whose balance contributes to a sustainable and livable environment.

The extensive use of advanced computing techniques allowed both the real time decision-making in handling multiple data during the planning process as well as the optimization of the phasing of the projects at the interconnected various scales. These tools enabled an innovative planning process addressing multiple objectives simultaneously, which was not possible without computing.

\section{Acknowledgements}

Special thanks to Arif Osmani and Atif Osmani of the Osmani Group, Petros Kanas of Doxiadis Associates, Peter Morrison and Ziyad Mahmoud of RMJM, and our colleagues Eugenia Chatzistavrou, Demos Lappas, and Vicky Sagia for their contribution to this project, to Dimitris Papadopoulos, who initiated this collaboration, to A. Salim, E. Marinou, E. Tzavellou, and to the team's transportation consultant Panos Kostaninidis.

\section{References}

[1] The World Bank (2013) Data: Population Growth. http://data.worldbank.org/indicator/SP.POP.GROW

[2] Economist Intelligent Unit (2012) A Summary of the Livability Ranking and Overview, August. 7 www.eiu.com

[3] Kyrtsis, A. (2006) Constantinos A. Doxiadis, Essays, Plans, Settlements. Ikaros, Athens.

[4] Zofnass Program for Sustainable Infrastructure at the Harvard University Graduate School of Design and the Institute for Sustainable Infrastructure (2013) ENVISION—A Rating System for Sustainable Infrastructure. 